\title{
Research on Loading Characteristics of Continuous Miner Based on Coal and Rock Particles Fluidity Effect
}

\section{You Chen}

Taiyuan University of Science and Technology https://orcid.org/0000-0003-4653-721X

Hong Zhang ( $\square$ hexie007@tyust.edu.cn )

Taiyuan University of Science and Technology

Guohua Li

Taiyuan University of Science and Technology

Honghong Yan

Taiyuan University of Science and Technology

\section{Zhihong Zhang}

Taiyuan University of Science and Technology

\section{Xiaojuan Sun}

Taiyuan University of Science and Technology

\section{Research}

Keywords: Continuous miner, Feeder star wheel, Discrete element method, Coal fluidity, Loading efficiency, Energy consumption

Posted Date: November 24th, 2020

DOl: https://doi.org/10.21203/rs.3.rs-111738/v1

License: (c) (i) This work is licensed under a Creative Commons Attribution 4.0 International License. Read Full License 


\title{
Research on loading characteristics of continuous miner based on coal and rock particles fluidity effect
}

\author{
You Chen, Hong Zhang, Guohua Li, Honghong Yan, Zhihong Zhang, Xiaojuan Sun \\ School of Mechanical Engineering, Taiyuan University of Science and Technology, Taiyuan, \\ 030024, China
}

Corresponding author: Hong Zhang, e-mail: hexie007@tyust.edu.cn

\begin{abstract}
The interaction mechanism between the star wheel arm and coal particles is the theoretical basis for the research of the feeder star wheel device. Based on the discrete element theory, the motion equation of coal particles in the process of coal harrowing with the feeder star wheel was established. With the aid of EDEM software, the coal model of the continuous miner with the simulation structure of coal wall, ground, feeder star wheel, and coal pile was reconstructed. The influence of the parameters includes the number of the arm of the star wheel, the height of the arm, and the inclination angle of the feeder on the loading efficiency and energy consumption of the feeder star wheel was revealed. The results have been shown that the fluidity effect of coal particles in the active zone of the material pile has been observed. The loading efficiency and torque of the feeder star wheel have been affected by this effect. The loading efficiency and energy consumption have been increased with the increase in the number of arm and height of the arm. The loading efficiency of feeder inclination angle $14^{\circ}$ is the highest and the energy consumption is the lowest.
\end{abstract}

Keywords: Continuous miner; Feeder star wheel; Discrete element method; Coal fluidity; Loading efficiency; Energy consumption

\section{Introduction}

Continuous miner equipment plays an important role in underground mining(Zhang et al. 2016; Gao and Ma 2017), and it is applied in the thin coal and rock seam, medium-thick coal and rock seam, and thick coal and rock seam(Yang et al. 2020). Among them, the feeder star wheel is one of the main working mechanisms of the continuous miner. Its function is to collect and rake the broken coal and rock of the cutting mechanism to the intermediate conveyor. Improving loading efficiency and reducing energy consumption is the premise of improving the performance of continuous miners(Zhang 2019). Generally speaking, the research on loading efficiency and energy consumption of the feeder star wheel is mainly based on physical prototype experiments and theoretical calculation. Its shortcomings are mainly manifested in the coal and rock loading experiment on the physical prototype, which has great structural limitations in parameter change. It is difficult to use the continuum theory to deal with the problem of bulk materials directly and it needs to be estimated by combining the relevant empirical coefficients. As a new method of bulk material analysis, the discrete element method has been widely used in the field of the shearer. It also provides a powerful supporting tool for simulation, analysis, and observation of particle flow movement(Wang et al. 2010). The discrete element method is applied to the simulation research of shearer drum performance in domestic and foreign research institutions(Mao et al. 2017; Linh et al. 2019). The complex simulation of the cutting and loading process and the accurate analysis of the 
effect of multi-parameter loading are realized. It also provides a new method to study the loading performance of the feeder star wheel of the continuous miner.

On the research trends of loading efficiency and energy consumption of continuous miner, Nosenko et al. (2017) applied for a patent that can adjust the arm height of the star wheel to reach the loading efficiency and energy consumption of the adjustable feeder star wheel. Otrokov et al. (2015) deduced the calculation formula of the loading efficiency and energy consumption of the star wheel without considering the traveling speed of the roadheader and taking the number of star wheel arm, structure form of the star wheel, and height of the arm as variables. Wang (2005) conducted experimental research on the parameters of the feeder star wheel of the roadheader. It is concluded that the loading effect of the knife-shaped star wheel with a speed over $50 \mathrm{r} / \mathrm{min}$ is better. Zhang (2006) proposed a method for determining the structural dimensions such as the number of arms and the height of the arm and the approximate calculation method for the loading power of the feeder wheel star. Through theoretical analysis, Ji (2010) concluded that the smaller the inclination angle of the feeder, the smaller the loading power required by the feeder star wheel. Zhang (2012) studied the influence of insertion depth on loading efficiency. Li (2011) proposed to make the scraper conveyor the most forward position relative to the feeder star wheel to improve self-loading efficiency. Yang (2017) introduced the discrete element method to analyze the loading efficiency. It is concluded that a smaller loading angle is easier to solve the problem of unbalanced loading.

From the above analysis, at present, the research on loading efficiency and energy consumption of continuous miner has made some progress, but most of them are still at the stage of theoretical exploration or laboratory experiments. To accurately grasp the calculation method of loading efficiency and energy consumption of the feeder star wheel, the following bottleneck problems still need to be solved:

- The model of coal and rock loading in the feeder star wheel of the continuous miner is not true enough. The traditional laboratory tests did not consider the effect of walking speed on loading coal and rock. The walking speed affects the movement state of the pile particles to a certain extent.

- The research on loading efficiency and energy consumption is not comprehensive and only considers one of the indicators. Loading efficiency and energy consumption are the indicators that the feeder star wheel must consider to improve the performance of the whole machine.

- The mechanism of interaction between the star wheel arm and coal and rock particles is not completely clear. The process of loading coal and rock by the feeder star wheel is accompanied by the movement of coal and rock particles. Unable to explain or judge the influence regularity of various variables on loading efficiency and energy consumption. Can not provide a theoretical basis for design improvement.

Therefore, in response to the above problems, the author establishes a discrete element simulation model for loading coal and rock by the feeder star wheel of a continuous miner. Using EDEM post-processing to explore the mechanism of interaction between star wheel arm and coal and rock particles, and discuss the influence regularity of each main variable parameter on loading efficiency and energy consumption one by one. The above research is an attempt to apply the discrete element method to the study of the characteristics of the coal and rock loaded on the star wheel. Systematically consider the influence of the advancement of the walking unit. It is helpful to promote the fine research of coal and rock loading. 


\section{Materials and methods}

\subsection{Mathematical model for star wheel loading}

\subsubsection{Motion equation for coal and rock particles}

The process of loading coal and rock by the feeder star wheel can assume that the coal and rock particles are discrete bodies. The discrete bodies exhibit complex motion properties due to the mutual force. In the coal and rock particle system, take anyone particle ball i, it's affected by the $j$ of the ball, is shown in Fig. 1. The motion equation of particle ball $i$ is(Jiang et al. 2014)

$$
m_{\mathrm{i}} \frac{\mathrm{d} \boldsymbol{V}_{\mathrm{i}}}{\mathrm{d} t}=m_{\mathrm{i}} \mathbf{g}+\sum_{j=1}^{n_{\mathrm{i}}}\left(\boldsymbol{F}_{\mathrm{n}, \mathrm{ij}}+\boldsymbol{F}_{\mathrm{t}, \mathrm{ij}}\right)
$$

where $m_{\mathrm{i}}$ is the mass of the particle ball $\mathrm{i}, \mathrm{kg} ; \boldsymbol{V}_{\mathrm{i}}$ is the velocity of the particle ball $\mathrm{i}, \mathrm{m} / \mathrm{s} ; t$ is time, $\mathrm{s} ; \boldsymbol{g}$ is the acceleration of gravity, $\mathrm{m} / \mathrm{s}^{2} ; \boldsymbol{F}_{\mathrm{n}, \mathrm{j}}$ is the normal contact force between the particle ball $\mathrm{i}$ and $\mathrm{j}, \mathrm{N} ; \boldsymbol{F}_{\mathrm{t}, \mathrm{j} j}$ is the tangential contact force between the particle ball $\mathrm{i}$ and $\mathrm{j}, \mathrm{N}$.

In addition to the action of gravity and collision force, the particle ball $\mathrm{i}$ is also affected by two moments, namely the moment $\boldsymbol{T}_{\mathrm{t}, \mathrm{ij}}$ caused by the tangential force and the rolling friction moment $\boldsymbol{T}_{\mathrm{r}, \mathrm{j} \text {. }}$. From the moment balance equation

$$
I_{\mathrm{i}} \frac{\mathrm{d} \omega_{\mathrm{i}}}{\mathrm{d} t}=\sum_{j=1}^{n_{\mathrm{i}}}\left(\boldsymbol{T}_{\mathrm{t}, \mathrm{ij}}+\boldsymbol{T}_{\mathrm{r}, \mathrm{ij}}\right)
$$

where $I_{\mathrm{i}}$ is the moment of inertia of the particle ball $\mathrm{i}, \mathrm{kg} \cdot \mathrm{m}^{2} ; \omega_{\mathrm{i}}$ is the angular velocity of the particle ball $\mathrm{i}, \mathrm{rad} / \mathrm{s}$.

Under the action of the above forces and moments, the speed, rotation speed, and position change of the particle ball i under the time step $\Delta t$ are expressed as

$$
\begin{gathered}
\boldsymbol{V}_{\mathrm{i}}=\boldsymbol{V}_{\mathrm{i}, 0}+\frac{\mathrm{d} \boldsymbol{V}_{\mathrm{i}}}{\mathrm{d} t} \Delta t \\
\boldsymbol{\omega}_{\mathrm{i}}=\boldsymbol{\omega}_{\mathrm{i}, 0}+\frac{\mathrm{d} \boldsymbol{\omega}_{\mathrm{i}}}{\mathrm{d} t} \Delta t \\
x_{\mathrm{i}}=x_{\mathrm{i}, 0}+\boldsymbol{V}_{\mathrm{i}} \Delta t
\end{gathered}
$$

where $V_{\mathrm{i}, 0}$ is the initial velocity of the particle ball $\mathrm{i}, \mathrm{m} / \mathrm{s} ; \boldsymbol{\omega}_{\mathrm{i}, 0}$ is the initial angular velocity of the particle ball $\mathrm{i}, \mathrm{rad} / \mathrm{s} ; x_{\mathrm{i}, 0}$ is the initial position of the particle ball $\mathrm{i}$.



Fig. 1 Collision analysis of two spherical coal particles in the DEM model

\subsubsection{Evaluation index of loading performance}


The theoretical loading efficiency of the feeder star wheel of the continuous miner is obtained by calculating the coal and rock loading area per revolution of a single arm and the average height of the arm, calculating the loadable mass of the single-arm, and multiplying the speed and the number of the arm of the star wheel.

The area of coal and rock loaded per revolution of a single-arm (Li et al. 2013) is

$$
A=\pi\left(\frac{D}{2}\right)^{2} \frac{\alpha}{360^{\circ}}-\pi\left(\frac{d}{2}\right)^{2} \frac{\alpha}{360^{\circ}}
$$

where $A$ is the area of coal and rock loaded per revolution of a single-arm, $\mathrm{m}^{2} ; D$ is the diameter of the outer circle of the star wheel, $\mathrm{m} ; d$ is the diameter of the inner circle of the star wheel, $\mathrm{m} ; \quad a$ is the angle between the star wheel arm, $\left(^{\circ}\right)$.

The mass of coal and rock loaded per revolution of a single-arm is

$$
Q_{1}=A \times h \times \varnothing \times \rho
$$

where $Q_{1}$ is the mass of coal and rock loaded per revolution of a single-arm, $\mathrm{kg}$; $h$ is the average height of the star wheel arm, m; $\phi$ is the loading factor, $0.68 ; \rho$ is the density of coal, $\mathrm{kg} / \mathrm{m}^{3}$.

The loading efficiency of $2 Z$-arm star wheels per second is

$$
Q=\frac{1}{60} \times 2 \times Z \times n \times Q_{1}
$$

where $Q$ is the loading efficiency of $2 Z$-arm star wheels per second, $\mathrm{kg} / \mathrm{s} ; Z$ is the number of star wheel arm; $n$ is the speed of the star wheel, $\mathrm{r} / \mathrm{min}$.

The calculation of energy consumption is mainly based on the analysis of the torque required by the star wheel in the process of raking coal, without considering the energy loss of the star wheel rotation, the surface friction of the star wheel body and the feeder. Star wheel torque $\boldsymbol{T}$ is calculated by extracting the torque of coal and rock particles acting on the star wheel shaft. The gravity of the coal and rock material loaded per revolution of the $Z$-arm star wheel is

$$
\boldsymbol{w}_{\mathrm{Z}}=Z \times Q_{1} \times \mathbf{g}
$$

where $\boldsymbol{W}_{Z}$ is the gravity of the coal and rock material loaded per revolution of the star wheel, N.

The friction force to be overcome when the coal and rock material slides on the surface of the feeder is

$$
\boldsymbol{F}=\boldsymbol{W}_{\mathrm{Z}} f
$$

where $f$ is the friction factor between coal and rock and feeder.

The torque generated by the friction between the coal and rock material movement and the feeder is (Zhang 2006)

$$
\boldsymbol{T}=\boldsymbol{F} \frac{D}{2}
$$

\subsection{Simulation model establishment and boundary conditions}

Taking a certain type of continuous miner's feeder star wheel as the research object. This type of continuous miner adopts a knife-shaped three-arm star wheel loading form. The feeder width $B$ is $3150 \mathrm{~mm}$, the position of the loading device below ground level is $165 \mathrm{~mm}$, the star wheel rotation speed $n$ is $51 \mathrm{r} / \mathrm{min}$, the arm height $h$ is $80 \mathrm{~mm}$. The scheme of feeder star wheel rake coal and rock is shown in Fig. 2. According to the actual observation on the operation site of the continuous miner, the maximum $H$ of the coal and rock pile at the front of the feeder is about 1.5 $\mathrm{m}$. This article is set to $1.0 \mathrm{~m}$. The distance between the front end of the feeder and the coal and rock wall is calculated to be $1.5 \mathrm{~m}$. Coal and rock form accumulation angle $\Omega$ according to the 
natural accumulation state. The technical parameters related to simulation are set as follows. The number of star wheel arm $Z$ is $1 \sim 7$, the arm height $h$ is $50 \mathrm{~mm}, 80 \mathrm{~mm}$, and $110 \mathrm{~mm}$, the inclination of the feeder $\beta$ is $14^{\circ}, 19^{\circ}$, and $24^{\circ}$ respectively. Reference standard value: The star wheel rotation speed $n$ is $51 \mathrm{r} / \mathrm{min}$. When the loading device is located $165 \mathrm{~mm}$ below the ground, the angle $\beta$ of the feeder is $24^{\circ}$. The arm height $h$ is $80 \mathrm{~mm}$. The depth $S$ of the feeder inserted into the pile is $800 \mathrm{~mm}$. The traveling speed $V$ is $160 \mathrm{~mm} / \mathrm{s}$ (Zhang et al. 2010).

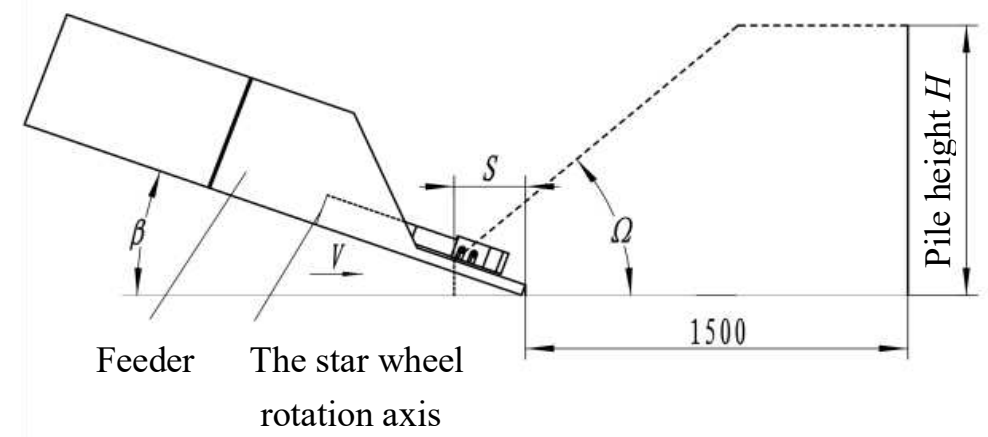

Fig. 2 Coal loading scheme of feeder star wheel

It is necessary to set model parameters and material properties, and define the particle properties to create the discrete element model of the feeder star wheel of the continuous miner. The properties of the material are coal, Poisson's ratio is 0.3 , density is $1400 \mathrm{~kg} / \mathrm{m}^{3}$, and shear modulus is $2 \times 10^{8} \mathrm{~Pa}$. The material properties of the feeder star wheel of the continuous miner are steel, Poisson's ratio is 0.3 , density is $7800 \mathrm{~kg} / \mathrm{m}^{3}$, and shear modulus is $8 \times 10^{10} \mathrm{~Pa}$, and define the interaction between the materials, the coefficient of restitution between coal and coal is 0.5 , the coefficient of static friction is 0.6 , and the coefficient of rolling friction is 0.05 . The coefficient of restitution between the coal and the feeder star wheel is 0.5 , the coefficient of static friction is 0.4 , and the coefficient of rolling friction is 0.05 (Wang et al. 2010). According to the requirements of the simulation model, the particle size of coal particles is set to $20 \sim 50 \mathrm{~mm}$, and the size is randomly distributed. Set particles and particles, geometry and geometry as no-slip contact models (Hertz-Mindlin).

The three-dimensional model of the feeder star wheel established in Solidworks is imported into the discrete element software EDEM. Considering the actual situation of the model, its simulation is divided into two steps. First, a static pile is generated. After calculation, the total mass of the coal and rock particles factory is set to $3969 \mathrm{~kg}$. Set the simulation time to $1.5 \mathrm{~s}$. The final EDEM simulation model of the feeder star wheel is shown in Fig. 3. Then use the built-in simulation deck function in the software. The simulation state output at time $1.5 \mathrm{~s}$ is used as the starting zero time of the star wheel rake coal and rock movement. Adjust the size of the simulation area to ensure that the entire feeder star wheel is in the simulation area. Add the feeder for horizontal straight motion, and set its speed and direction. Because the rotary linear composite motion in the EDEM software varies with the settings, first add the star wheels as the horizontal linear motion along the forward direction of the continuous miner, and then add the rotary motion. The time step is $20 \%$ of the Rayleigh time step(Tekeste et al. 2020). The rake time is $4.81 \mathrm{~s}$. 
Selectively save data and the save cycle is $0.1 \mathrm{~s}$.

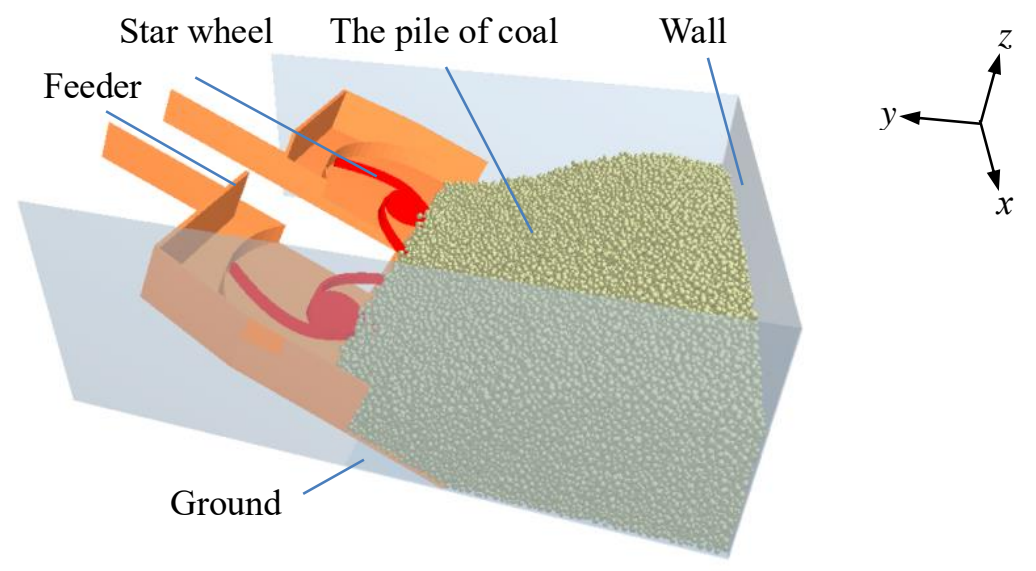

Fig. 3 Coal loading reconstruction model of star wheel loading in EDEM

\section{Results and discussion}

\subsection{Interaction mechanism between star wheel arm and coal particles}

In the process of raking coal, there is a complex interaction relationship between the star wheel arm and the coal particles. This relationship reveals the essence of changes in loading efficiency $Q$ and energy consumption $T$ by analyzing the movement law between coal particles and star wheel arm. The velocity vectors of coal particles at different moving moments of the star wheel arm are shown in Fig. 4. In Fig. 4. (a)(b)(c), Through EDEM post-processing, the coal particles are expressed in vector form, and the direction of the arrow indicates the direction of the particle velocity. The color is used to distinguish the velocity of the particles. Set the speed from low to high to blue and green respectively. As shown in Fig. 4. (a), the velocity of coal particles in the pile is close to zero, and the star wheel arm is not moving. The direction of the movement of coal particles is irregular and scattered. It can be seen from Fig. 4. (b) that when the arm movement of the star wheel is in contact with coal particles, the particles move away from the center of the star wheel, and the particles close to the upper side of the star wheel arm move upward. Besides, the larger the velocity of coal particles along the radial direction to the left of the star wheel arm indicates that the coal interaction with the star wheel arm is intense, and the coal fragmentation occurs accordingly. Fig. 4. (c) is the vector motion image of the particles when the star wheel arm leaves the coal. It is found that the coal particles appear to fall back. This indicates that the space formed after the star wheel rakes through the coal material pile needs to be supplemented by coal particles. Through EDEM post-processing observation and analysis, the general diagram of coal particle movement in the process of raking coal with the feeder star wheel is shown in Fig. 4. (d) (Otrokov et al. 2018). Take the sliding surface as the boundary to divide the material pile into two areas: movement area I and movement area II, and the red, blue, and green arrows represent the direction of movement of coal particles. It can be seen from Fig. 4. (d) that when the feeder star wheel is loaded with coal particles, the walking unit continuously pushes the feeder star wheel to the pile. As the next adjacent star wheel arm rake enters the pile, the coal particles in front of it begin to move. A part of the coal particles are pushed up, and at the same time, a part of the coal particles are held by the star wheel arm and away from the pile. The pile collapsed after the star wheel arm passed, in the first stage, the coal particles in the active layer 
pile fall vertically. In the second stage, the coal particles slide along the slip line, thus reducing the adhesion between coal particles. If the coal particles are captured by the next adjacent star wheel arm at this time, it indicates that the coal particles in the active layer of the pile have a fluidity effect(Otrokov et al. 2018). Besides, the moving coal particles in the movement zone $\mathbf{I}$ will have a vortex phenomenon. The reason is that the coal particles move in the direction of least resistance during the mutual interaction between the star wheel arm and the coal particles. This provides basic theoretical support for the analysis of star wheel loading performance.

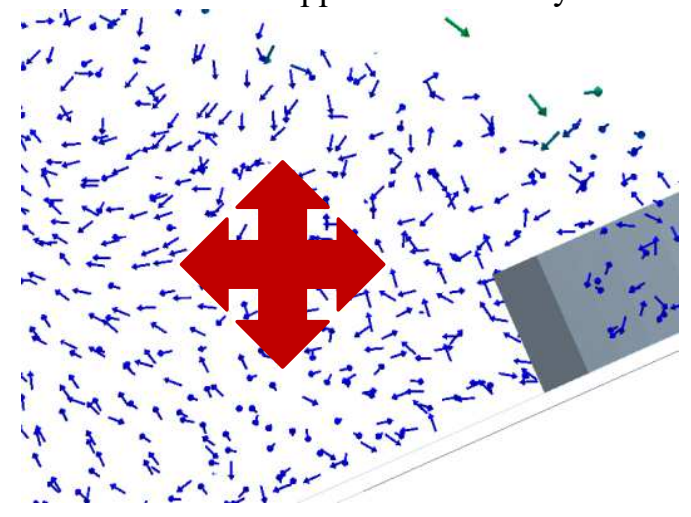

(a) At rest

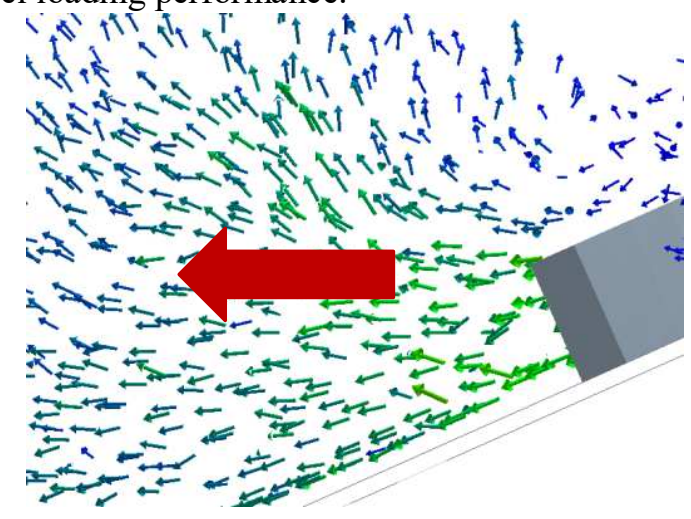

(b) Movement of the instantaneous

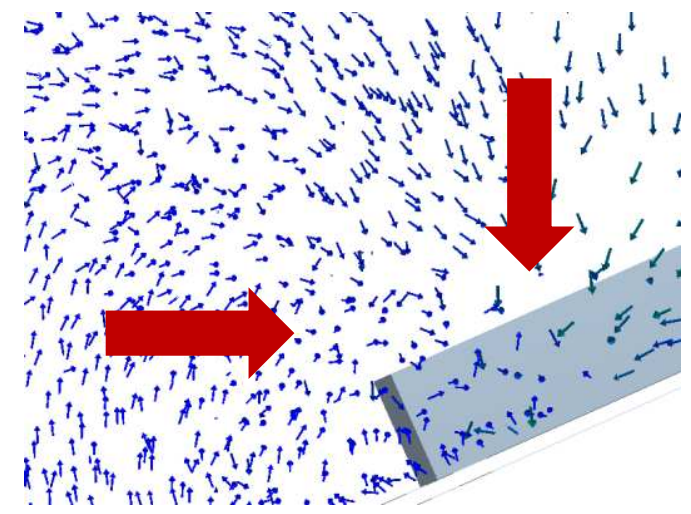

(c) Leave coal and rock

Sliding surface Edge of pile Feeder Star wheel arm The rotation axis of star wheel



(d) One cycle of movement

Fig. 4 The velocity vector of coal particles at different movement times of star wheel arm 


\subsection{Analysis of star wheel loading performance}

Based on the EDEM simulation model of the feeder star wheel shown in Fig. 3., respectively simulate and analyze the continuous forward working condition of the walking unit. The influence of three variable parameters of arm number $Z$, arm height $H$, and feeder inclination $\beta$ on loading efficiency $Q$ and energy consumption $T$ in the process of rake coal.

\subsubsection{Analysis of star wheel loading efficiency}

Fig. 5. shows the $Q$ curve of loading mass flow rate corresponding to different variable parameters. Fig. 5. (a) shows the loading mass flow rate $Q$ change process when the arm height $h$ is $80 \mathrm{~mm}$, the feeder inclination angle $\beta$ is $24^{\circ}$, and the number of star wheel $\operatorname{arm} Z$ is $1,3,5$, and 7. It can be obtained from Fig. 5. (a) the loading mass flow rate $Q$ increases as the number of star wheel $\operatorname{arm} Z$ increases. The loading mass flow rate $Q$ shows the characteristic of periodic change law. For a single arm star wheel, the period is about $1.18 \mathrm{~s}$. This shows that the period of loading mass flow rate is related to the number of $\operatorname{arm} Z$ and the rotation speed $n$ of the star wheel. At the same time, as the feeder moves forward continuously, the insertion depth $S$ of the material increases, and the star wheel arm can rake the material fully, leading to the loading mass flow rate $Q$ increasing with time $t$. Fig. 5. (b) shows loading mass flow rate $Q$ under 3 -arm star wheel, $24^{\circ}$ feeder inclination angle, and different arm height $h$. It is found that the loading mass flow rate $Q$ increases with the increase of arm height $h$. Because the pile is a certain amount of coal, the flow of coal is slow at the beginning (see Fig. 4. (d)). Moreover, the coal in the pile can not be replenished after the star wheel rake. The results show that the difference of wave peak of loading mass flow rate $Q$ with three arm height $h$ changes from small to large and then to small with time $t$. This shows that the size of the pile in front of the feeder and the material fluidity should be considered in the design of the star wheel arm height $h$. Fig. 5 (c) shows the loading mass flow rate $Q$ under different feeder inclination angle $\beta$. That is, set the number of arm $Z$ to 3 and the arm height $h$ to $80 \mathrm{~mm}$. The change of loading mass flow rate $Q$ of the star wheel under the working conditions of $14^{\circ}, 19^{\circ}$ and $24^{\circ}$ feeder inclination angle $\beta$. It can be seen from Fig. 5 (c) that the loading mass flow rate $Q$ of the feeder star wheel increases with the decrease of the feeder inclination angle $\beta$. Due to the periodic loading of coal by star wheel, the coal falling on the scraper conveying device have a certain impact on the scraper chain. The protection of the scraper chain should be considered to enhance service life and stability of the scraper chain. 




(a) Different numbers of $\operatorname{arm} Z$

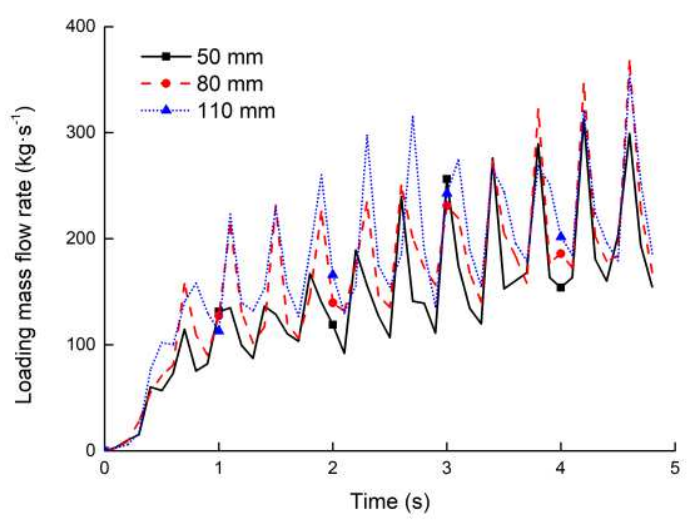

(b) Different heights of arm $h$

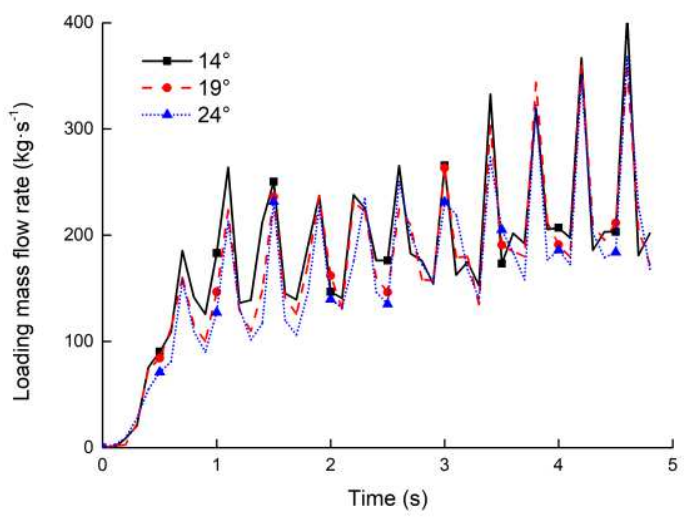

(c) Different inclination angles of feeder $\beta$

Fig. 5 Loading mass flow rate $Q$ of feeder star wheel under various parameters

\subsubsection{Analysis of star wheel energy consumption}

The feeder star wheel torque $T$ corresponding to each variable parameter is shown in Fig. 6 . Fig. 6. (a) shows the changing process of torque $T$ when the arm height $h$ is $80 \mathrm{~mm}$, the feeder inclination angle $\beta$ is $24^{\circ}$, and the arm number $Z$ is $1,3,5$, and 7. It can be seen from Fig. 6. (a) that with the increase of the number of star wheel $\operatorname{arm} Z$, the torque value $T$ also increases. The more the number of star wheel arm $Z$, the smaller the torque period. 7-arm star wheel shows good load characteristics. That is, the more the number of $\operatorname{arm} Z$, the more stable the load of the star wheel, the smaller the impact. Besides, for the single-arm star wheel torque $T$ appears zero value. The reason is that there is an empty range in the process of star wheel raking coal, and the star wheel arm is no longer subject to the force given by coal. Fig. 6. (b) shows the star wheel torque $T$ under different arm height $h$. With the increase of arm height $h$, the star wheel torque $T$ also increases. However, the first torque peak of $2295 \mathrm{~N} \cdot \mathrm{m}$ with an arm height $h$ of $80 \mathrm{~mm}$ is greater than the torque peak of $1367 \mathrm{~N} \cdot \mathrm{m}$ with an arm height $h$ of $110 \mathrm{~mm}$. The reason is that the star wheel with the arm height $h$ of $80 \mathrm{~mm}$ is affected by the fluidity of the coal, and in the first turn of the rake coal are unstable. Fig. 6. (c) shows the star wheel torque $T$ under different feeder inclination angle $\beta$. It is found that as the inclination angle $\beta$ of the feeder decreases, the star wheel torque $T$ decreases. Compared with the 3 feeder inclination angle $\beta$, the $14^{\circ}$ feeder inclination 
angle $\beta$ requires the smallest torque $T$ to rake coal. Due to the fluidity characteristics of coal, the peak torque of the star wheel exhibits a fluctuating law with time $t$. The control research on the drive device should be increased to enhance the stability and performance of the motor and reducer.

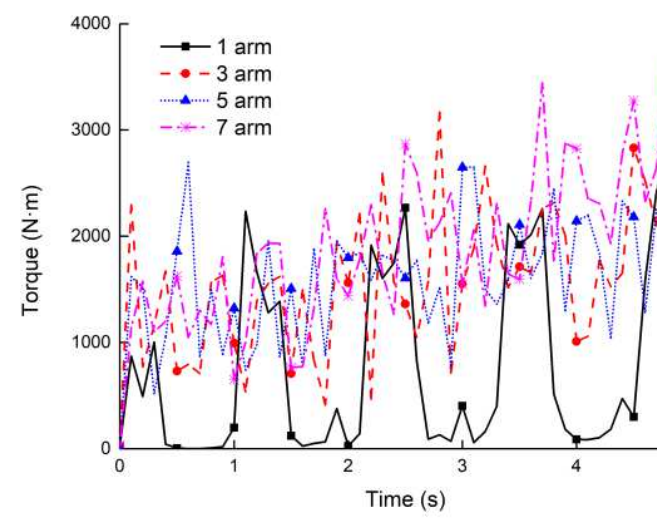

(a) Different numbers of $\operatorname{arm} Z$

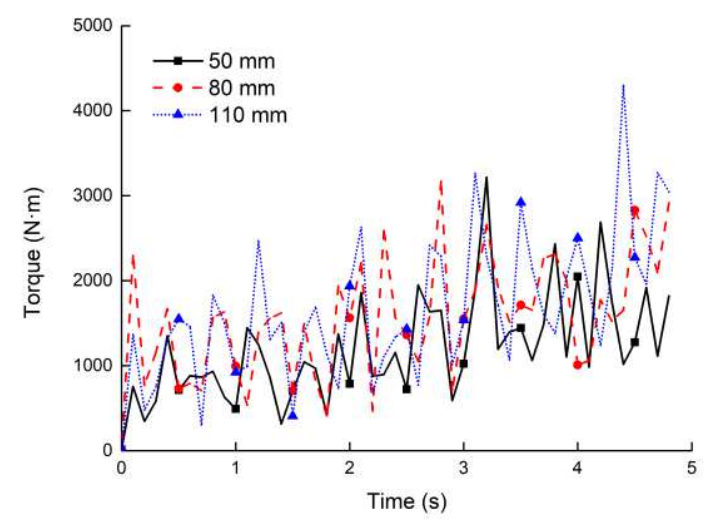

(b) Different heights of arm $h$

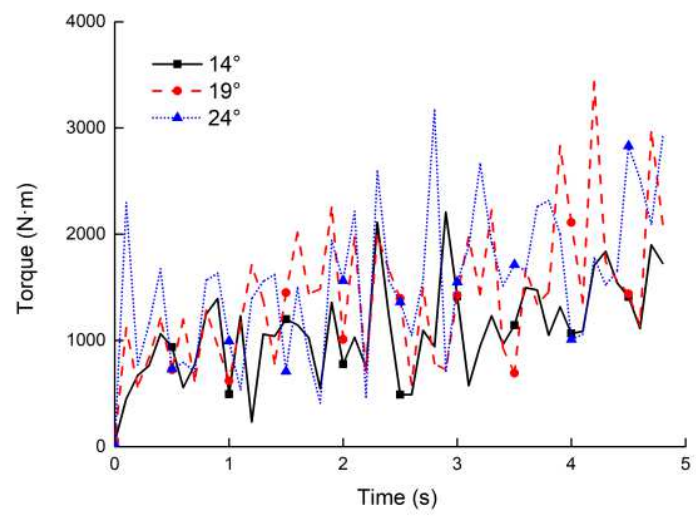

(c) Different inclination angles of feeder $\beta$

Fig. 6 Torque $T$ of feeder star wheel under various parameters

Compare the loading mass flow rate $Q$ (Fig. 5. (a)) and the star wheel torque $T$ (Fig. 6. (a)) of different star wheel $\operatorname{arm} Z$. It is found that the more the number of $\operatorname{arm} Z$, the higher the loading efficiency $Q$, but the greater the torque T. Comparing Fig. 5. (b) and Fig. 6. (b), it is concluded that the higher the star wheel $\operatorname{arm} h$, the higher the loading efficiency $Q$ but the greater the torque $T$. That is, the number of $\operatorname{arm} Z$ and the height of the $\operatorname{arm} h$ are positively related to the loading efficiency $Q$ and the energy consumption T. Comparing Fig. 5. (c) and Fig. 6. (c), it is found that the feeder inclination angle $\beta=14^{\circ}$ has the highest loading efficiency $Q$ and the lowest energy consumption $T$.

\section{Conclusion}

In this paper, the discrete element theory is used to establish the motion equation of coal particles in the process of feeder star wheel rake coal, and the theoretical calculation method of feeder star wheel loading efficiency $Q$ and energy consumption $T$ is given. With the help of EDEM software, the continuous miner feeder star wheel loading model was reconstructed. 
Discussed the movement characteristics of coal particles. The influence of the parameters, such as the number of $\operatorname{arm} Z$, the height of $\operatorname{arm} h$, and the inclination angle $\beta$ of the feeder, on the loading efficiency $Q$ and energy consumption $T$ of the star wheel, are revealed. The main conclusions are as follows:

(1) The coal action in contact with the star wheel arm is intense, and the crushing coal occur accordingly. The space formed after the star wheel rakes through the coal pile needs to be supplemented by coal particles. During the interaction between star wheel arm and coal particles, coal particles move in the direction of least resistance. Coal particles slide along the sliding line, reducing the adhesion between coal particles. If the coal particles are captured by the next adjacent star wheel arm at this time, the coal particles in the active layer of the pile exhibit fluidity effects. These influence the variation law of the loading efficiency $Q$ and torque $T$ of the feeder star wheel.

(2) The arm number $Z$ and arm height $h$ are positively correlated with loading efficiency $Q$ and energy consumption $T$. Under the premise of satisfying the loading efficiency $Q$, the number of star wheel $\operatorname{arm} Z$ and the star wheel arm height $h$ should be considered comprehensively to reduce energy consumption $T$. The rake coal loading efficiency $Q$ is the highest and the energy consumption $T$ is the smallest when the feeder inclination angle $\beta$ is $14^{\circ}$.

(3) The loading mass flow rate $Q$ and torque $T$ both exhibit periodic fluctuations. As a result, the conveyor scraper chain and star wheel are greatly impacted by coal. In-depth research is needed on the protection of the scraper chain and the control of the star wheel drive device. To improve the service life and stability of scraper chain and improve the performance of motor reducer. Further, improve coal transportation performance.

Acknowledgements The authors gratefully acknowledge the financial support provided by National Natural Science Foundation of China (Grant No. 52075355).

Author contributions The simulation and data analysis were conducted by You Chen. The manuscript was written by You Chen and Hong Zhang. Other authors provided some suggestions for the research.

Data availability All the data were collected in the simulation.

Code availability Not applicable.

\section{Compliance with ethical standards}

Conflict of interest The authors declare no conflicts of interest.

Open Access This article is licensed under a Creative Commons Attribution 4.0 International License, which permits use, sharing, adaptation, distribution and reproduction in any medium or format, as long as you give appropriate credit to the original author(s) and the source, provide a link to the Creative Commons licence, and indicate if changes were made. The images or other third party material in this article are included in the article's Creative Commons licence, unless indicated otherwise in a credit line to the material. If material is not included in the article's Creative Commons licence and your intended use is not permitted by statutory regulation or exceeds the permitted use, you will need to obtain permission directly from the copyright holder. To view a copy of this licence, visit http://creativecommons.org/licenses/by/4.0/.

\section{References}


Gao YF, Ma JG (2017) Current application and development status of domestic continuous miner. Coal Engineering 49(08): 145-148

Ji JW (2010) Influence of the turntable shape and the gathering apron inclination on the loading efficiency of roadheader. Mechanical Engineering and Automation (02): 108-110

Jiang Q, Li XB, Meng WJ (2014) Discrete element analysis on material in chutes of transfer station based on EDEM. Mining and Processing Equipment 42(04): 51-55

Li G, Gao CX, Xu JH (2013) Parameter matching and optimization on shovel and conveyor mechanism of roadheader. Coal Mine Machinery 34(04): 8-9

Li J (2011) Analysis and research of how to raise loading efficiency that stellated loader owns. Coal Mine Machinery 32(03): 65-66

Linh NK, Gabov VV, Giap DV, Tien PV (2019) Study of the influence of structure and parameters of loading and transporting devices of a cleaning combine on the efficiency of coal loading. In Journal of Physics: Conference Series (Vol. 1384, No. 1, p. 012036). IOP Publishing.

Mao J, Liu XY, Chen HY, Song QS (2017) Simulation of shearer drum cutting performance based on EDEM. Journal of China Coal Society 42(04): 1069-1077

Nosenko AS, Isakov VS, Domnitskiy AA, Shemshura EA, Zubov VV (2017) Improvement of loading and transport bodies of tunneling machines. In IOP Conference Series: Earth and Environmental Science (Vol. 87, No. 6, p. 062012). IOP Publishing.

Otrokov AV, Khazanovich GS, Afonina NB (2015) Physical simulation of loaders with scooping starwheels. Journal of Mining Science 51(2): 292-297

Otrokov AV, Khazanovich GS, Afonina NB (2018) Impact of design parameters on the efficiency of loading organs with gathering stars of the roadheaders. In International Conference on Industrial Engineering (pp. 401-410). Springer, Cham.

Tekeste MZ, Way TR, Syed Z, Schafer RL (2020) Modeling soil-bulldozer blade interaction using the discrete element method (DEM). Journal of Terramechanics 88: 41-52

Wang GQ, Hao WJ, Wang JX (2010) Discrete element method and its practice on EDEM. Northwestern Polytechnical University Press, Xi'an.

Wang SB (2005) Test and research on parameters of planetary gear loading mechanism for mine roadheader. Coal Science and Technology (09): 46-48

Yang SH, Zhou YC, Rui F, Zhang SH (2020) Development trend of thin coal seam mining and complete equipment technology. Coal Science and Technology 48(03): 49-58

Yang ZY (2017) Bulk material theory of simulation application with headroader. Coal Mine Machinery 38(06): 121-123

Zhang GD (2006) Design research on loading system of mine roadheader. Coal Science and Technology (10): 59-62

Zhang H, Zhang XK, Shi T (2016) Analysis on dynamics features and fatigue life of crawler walking mechanism applied in continuous miner. Coal Science and Technology 44(11): $110-115$

Zhang LH (2012) Analysis about the influence factors of EBZ220 roadheader's loading device structural design. Colliery Mechanical and Electrical Technology (06): 74-77

Zhang XF (2019) Study on loading and conveying mechanism style of mine gateway driving equipment. Coal Mine Machinery 40(07): 69-70

Zhang YL, Li ZQ, Zhou MP, Jiang XJ (2010) Application of EML340 continuous miner and related equipment in coal mine. Coal Science and Technology 38(12): 89-92 
Figures

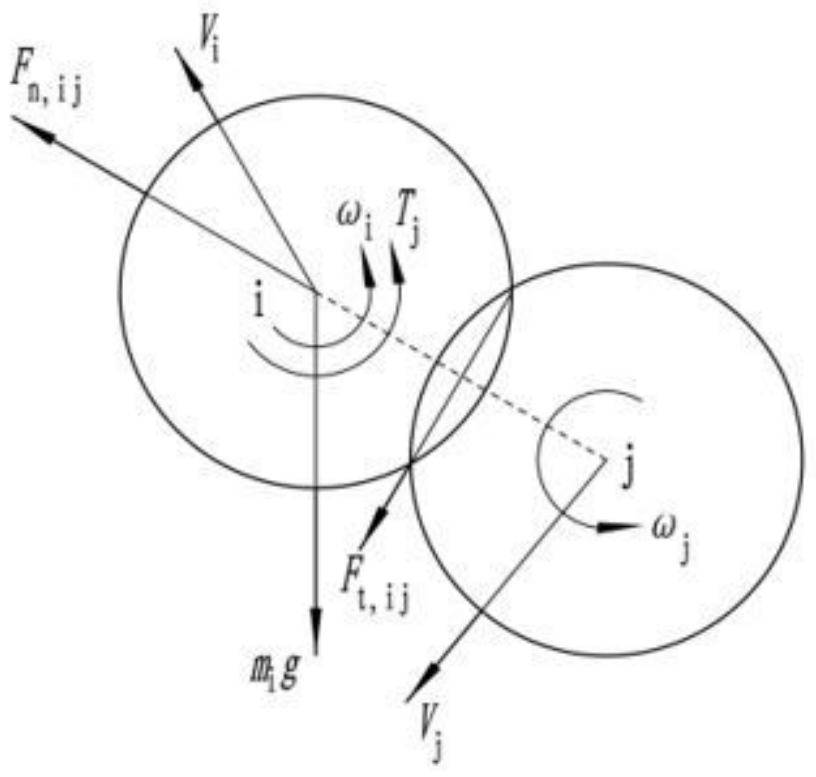

Figure 1

Collision analysis of two spherical coal particles in the DEM model



Figure 1

Collision analysis of two spherical coal particles in the DEM model 


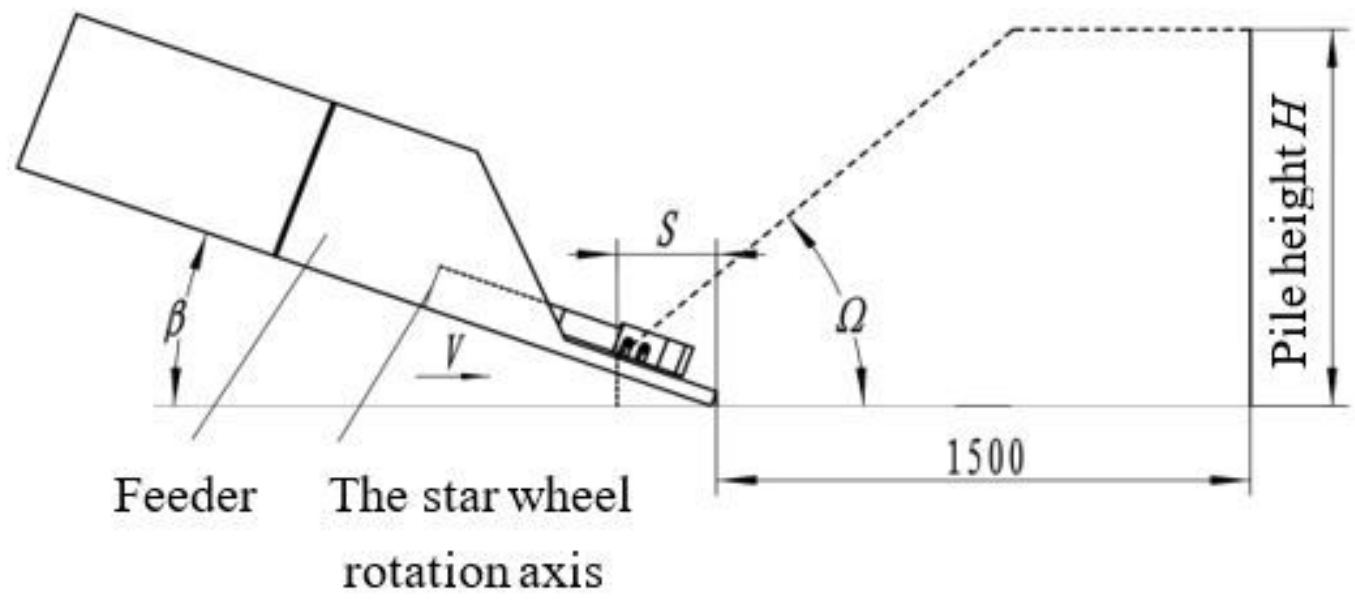

Figure 2

Coal loading scheme of feeder star wheel

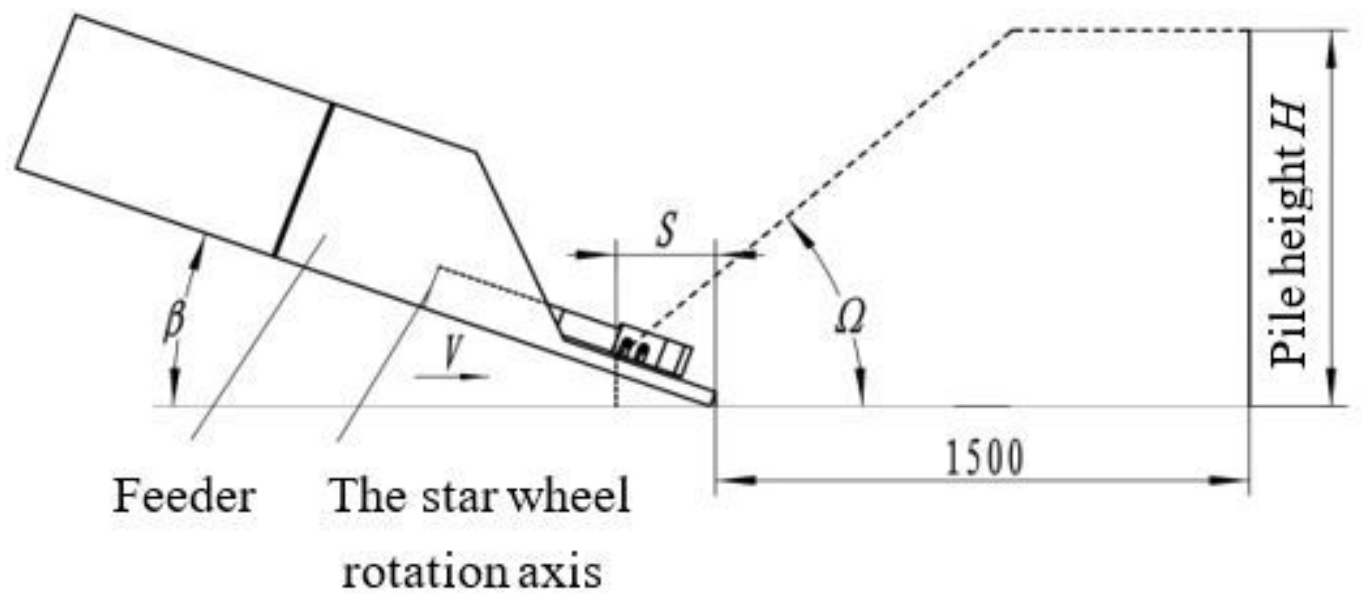

Figure 2

Coal loading scheme of feeder star wheel 


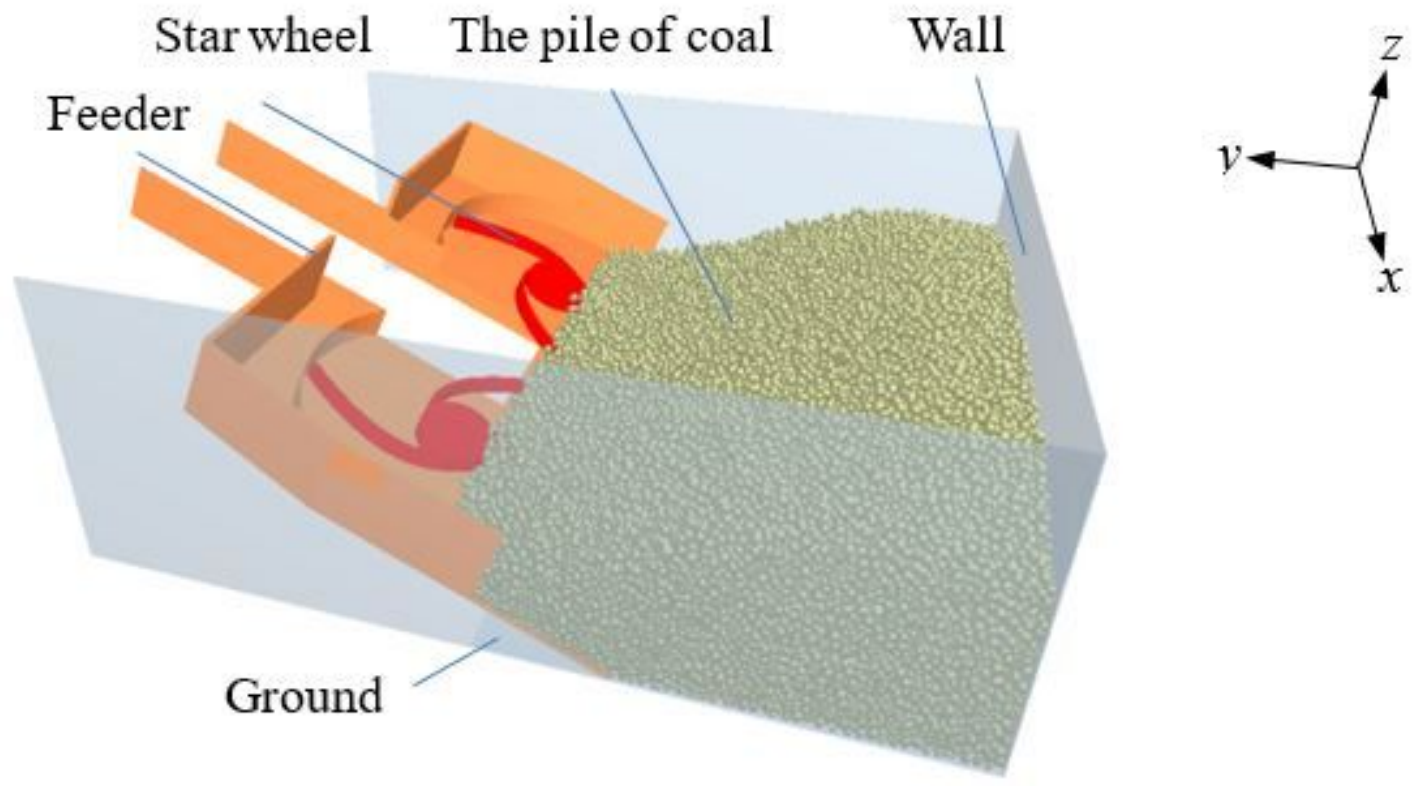

Figure 3

Coal loading reconstruction model of star wheel loading in EDEM
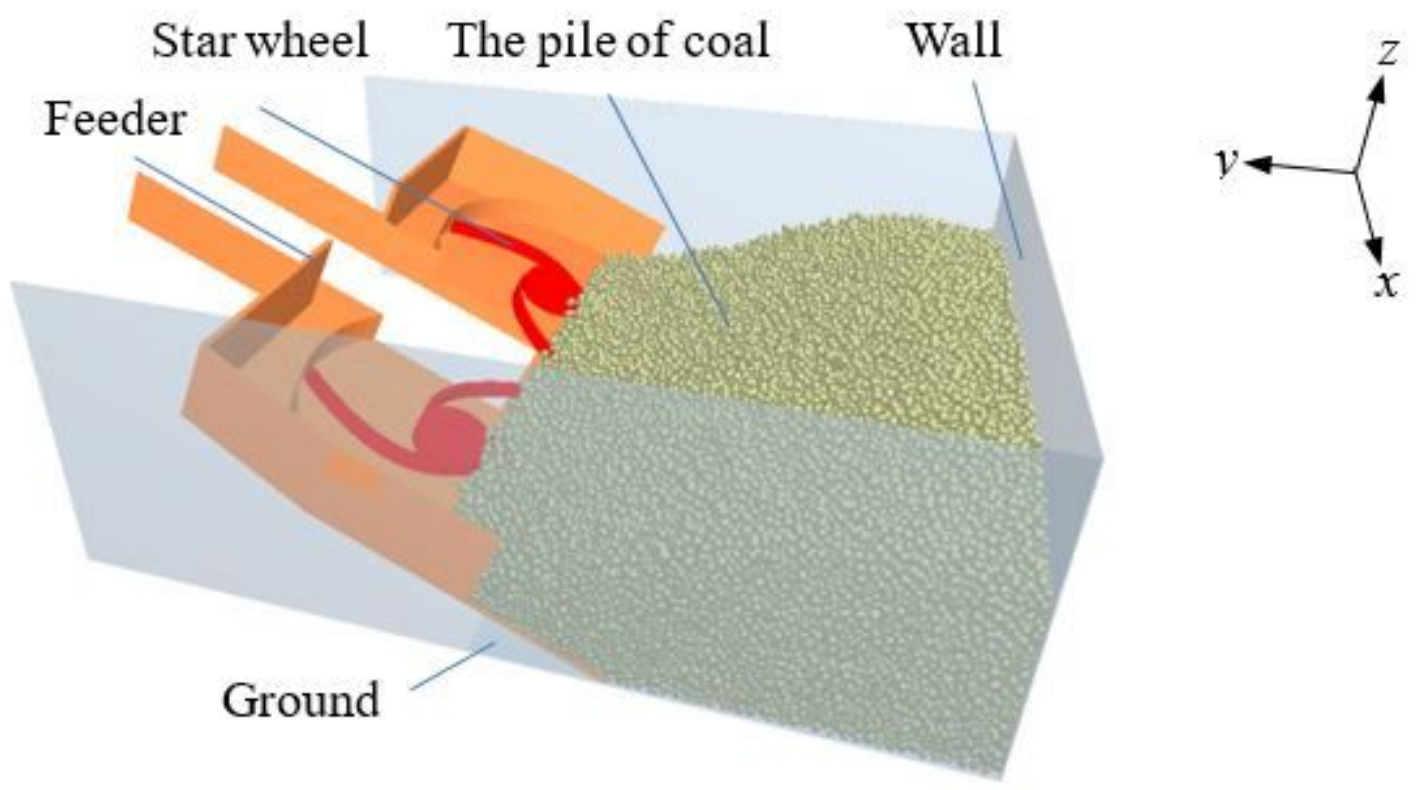

Figure 3

Coal loading reconstruction model of star wheel loading in EDEM 


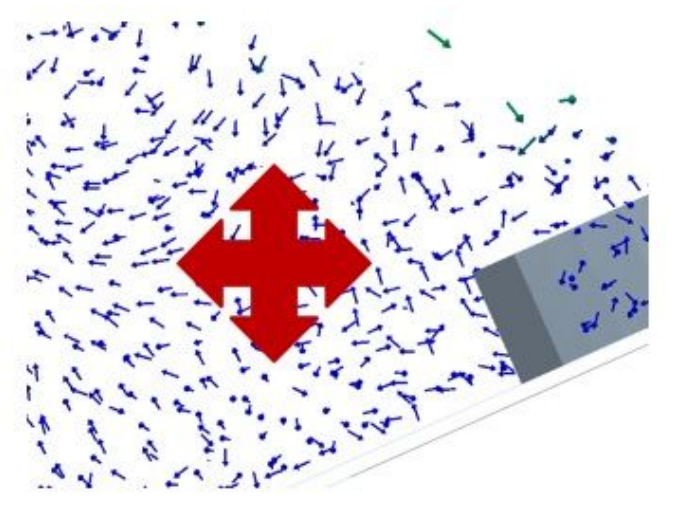

(a) At rest



(b) Movement of the instantaneous



(c) Leave coal and rock

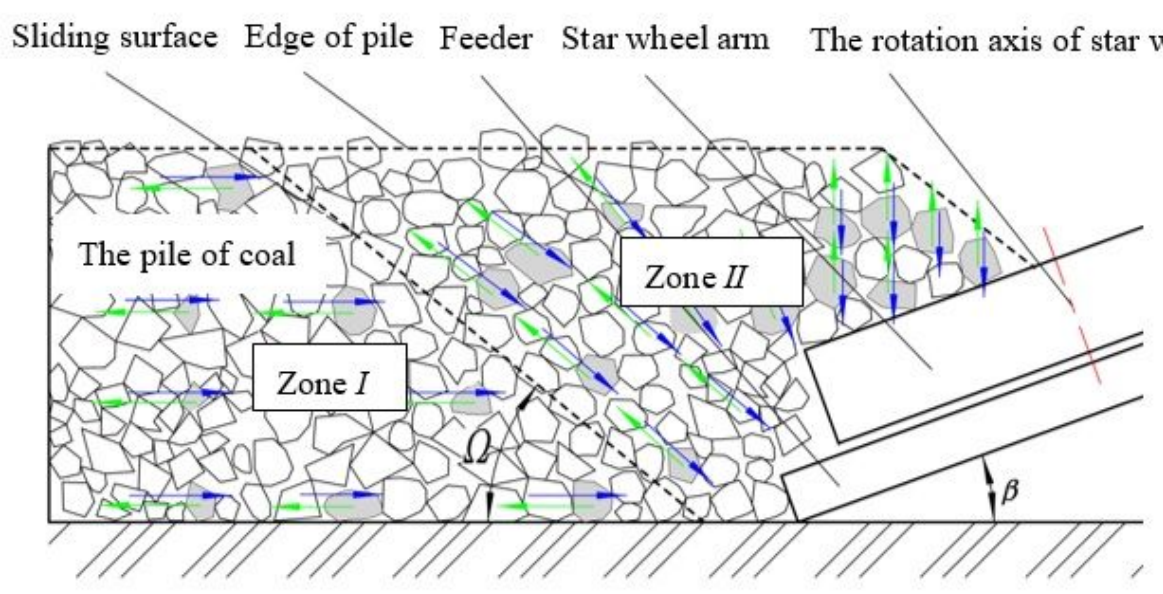

(d) One cycle of movement

\section{Figure 4}

The velocity vector of coal particles at different movement times of star wheel arm 


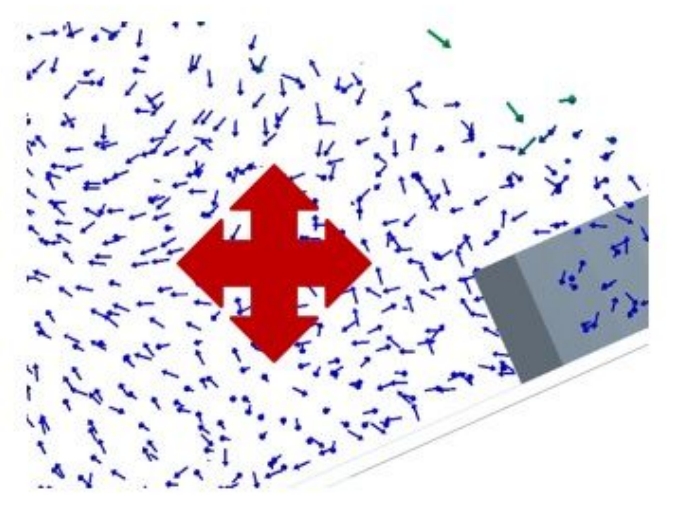

(a) At rest

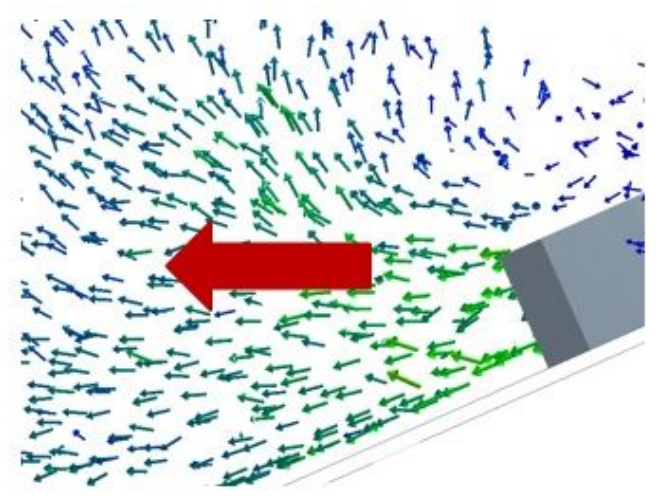

(b) Movement of the instantaneous

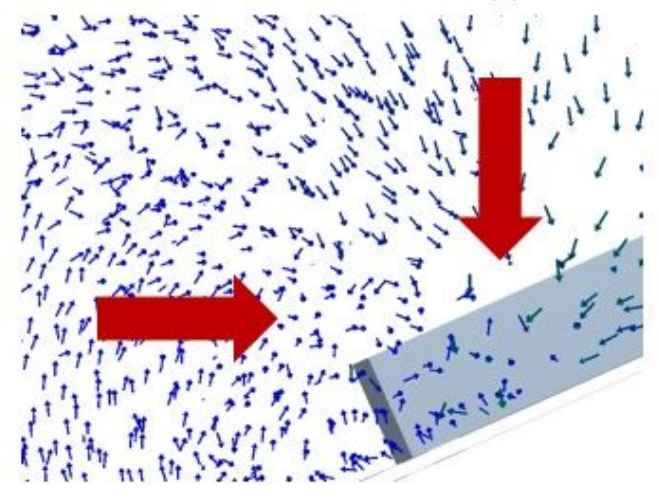

(c) Leave coal and rock

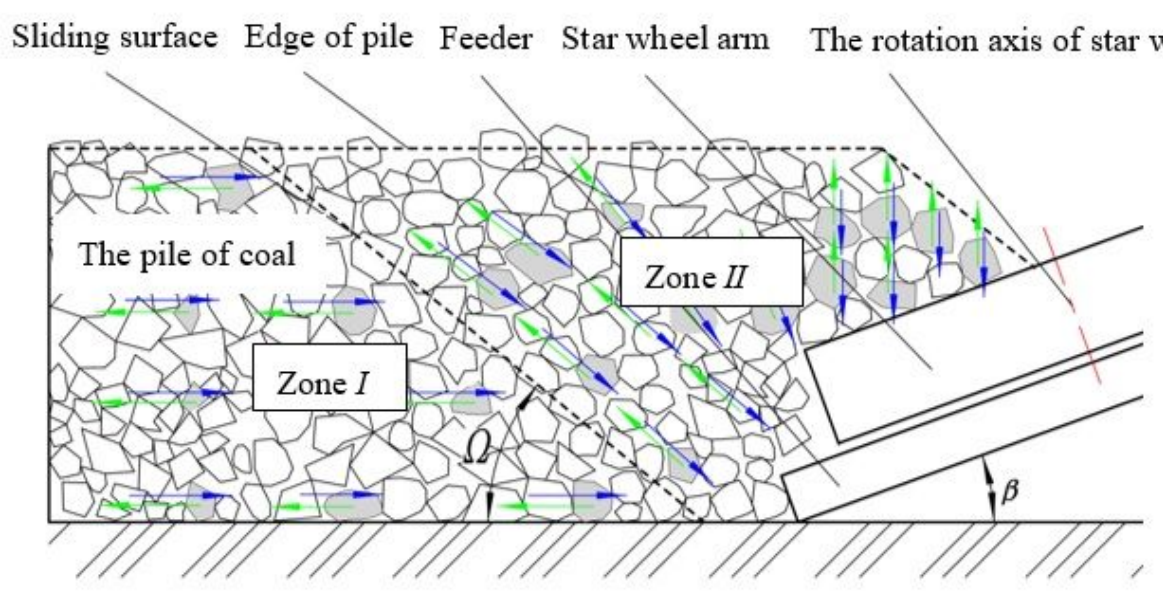

(d) One cycle of movement

\section{Figure 4}

The velocity vector of coal particles at different movement times of star wheel arm 


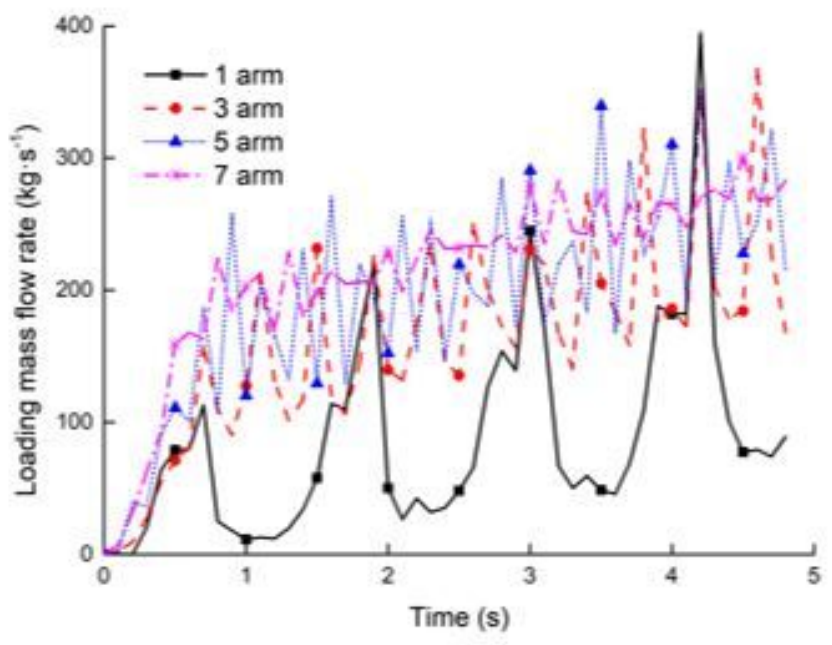

(a) Different numbers of $\operatorname{arm} Z$



(b) Different heights of $\operatorname{arm} h$

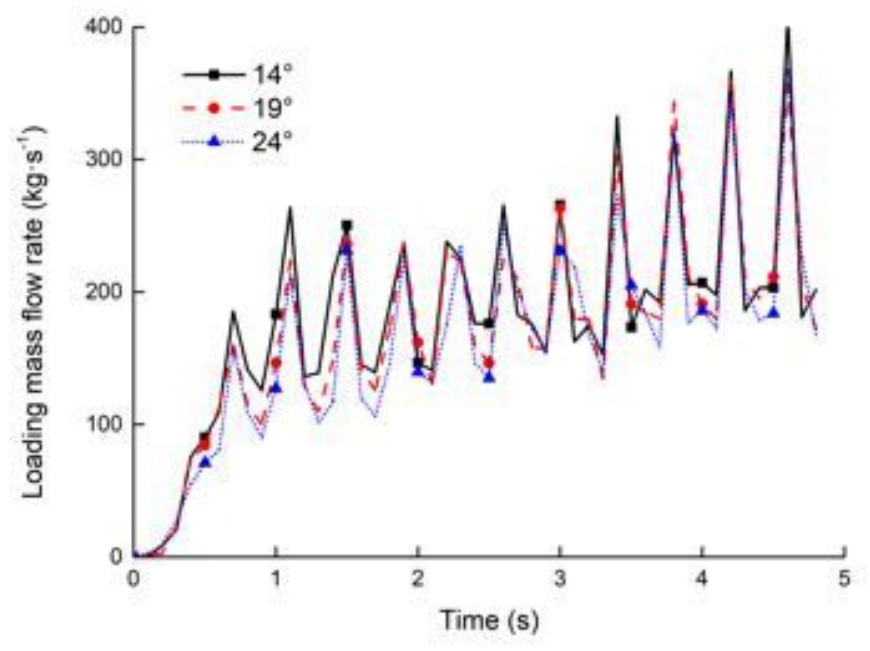

(c) Different inclination angles of feeder $\beta$

Figure 5

Loading mass flow rate $\mathrm{Q}$ of feeder star wheel under various parameters 


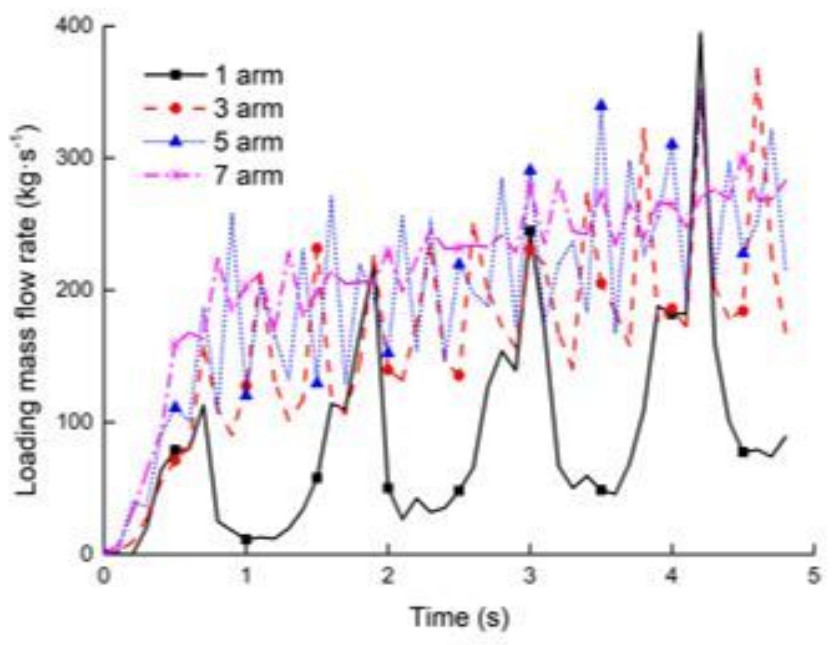

(a) Different numbers of $\operatorname{arm} Z$



(b) Different heights of $\operatorname{arm} h$

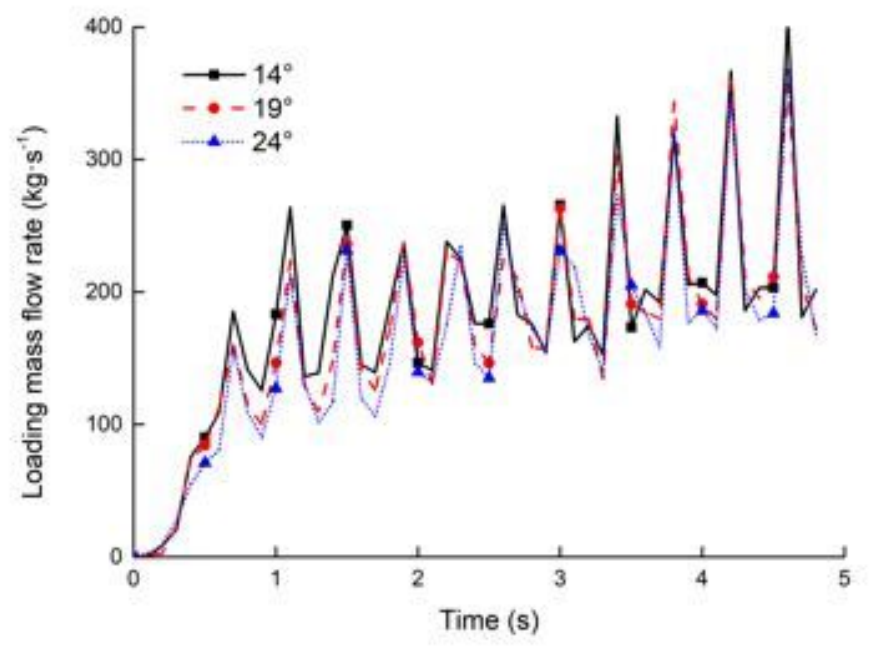

(c) Different inclination angles of feeder $\beta$

Figure 5

Loading mass flow rate $\mathrm{Q}$ of feeder star wheel under various parameters 


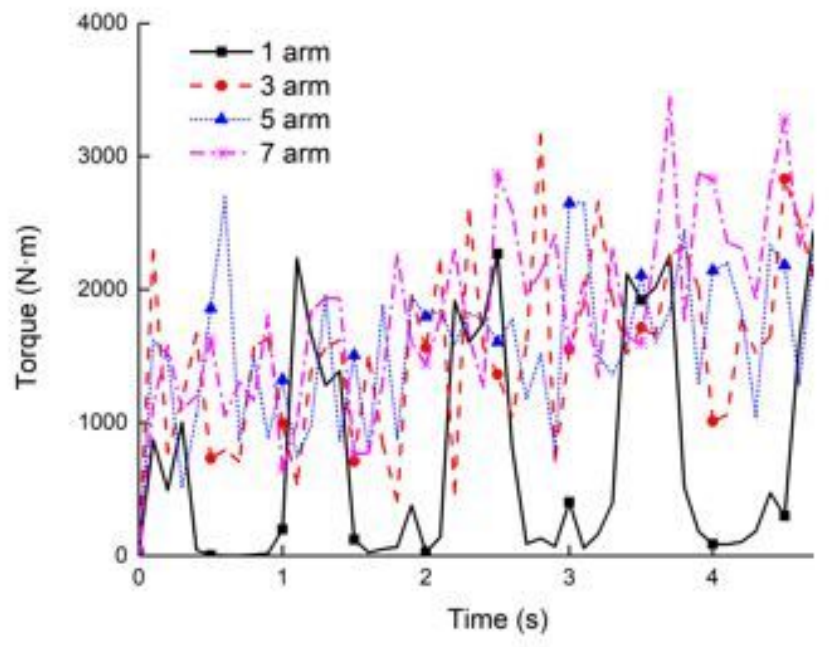

(a) Different numbers of $\operatorname{arm} Z$

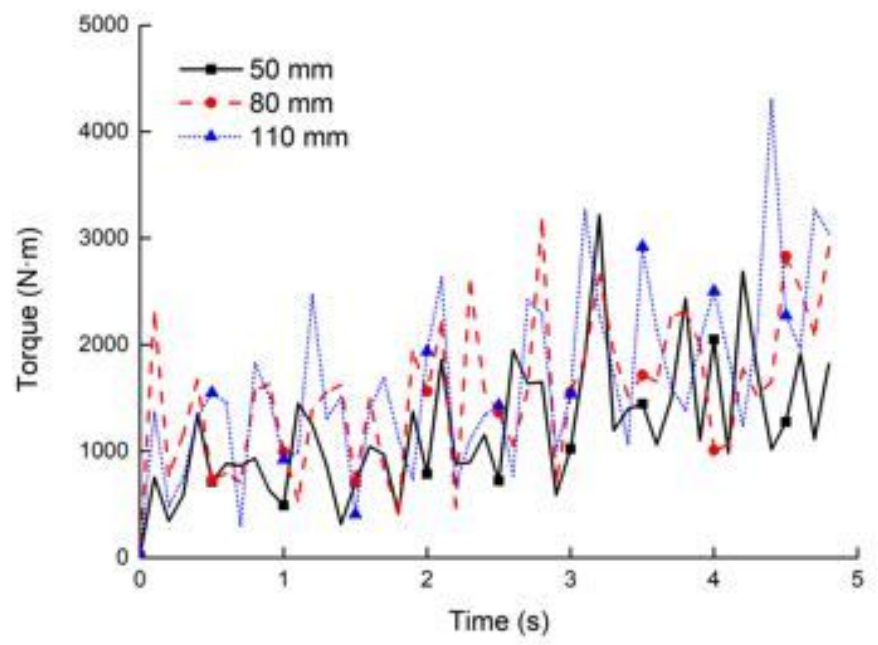

(b) Different heights of arm $h$



(c) Different inclination angles of feeder $\beta$

Figure 6

Torque $\mathrm{T}$ of feeder star wheel under various parameters 


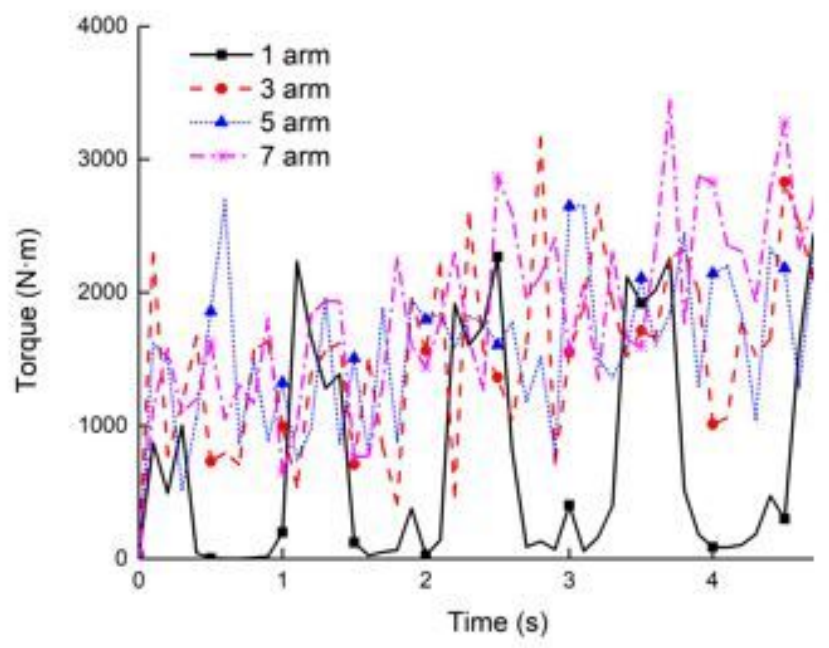

(a) Different numbers of $\operatorname{arm} Z$

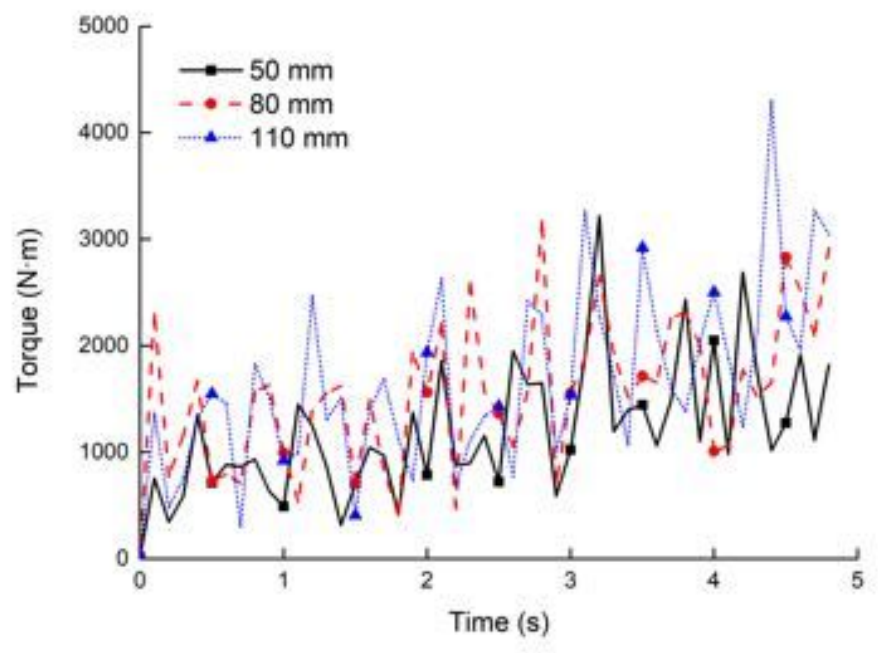

(b) Different heights of arm $h$

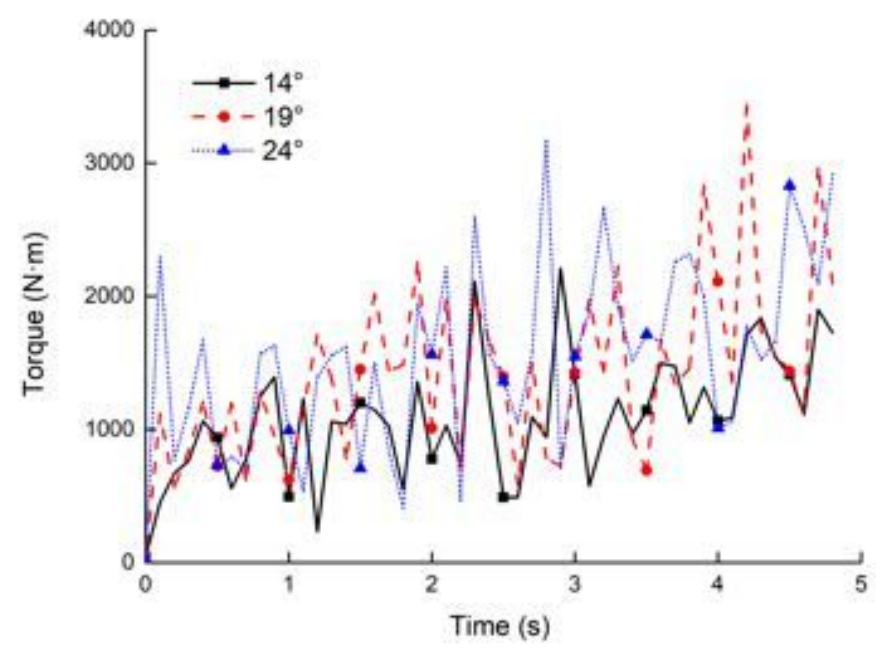

(c) Different inclination angles of feeder $\beta$

Figure 6

Torque $\mathrm{T}$ of feeder star wheel under various parameters 